\title{
Cinética de fermentação in vitro de fenos da parte aérea de mandioca
}

\author{
Kinetics of "in vitro" fermentation of the hay shoots of cassava
}

\author{
MARQUES, Kléria Maria de Souza ${ }^{1}$; ROCHA JÚNIOR, Vicente Ribeiro ${ }^{1 *}$; REIS, \\ Sidnei Tavares dos ${ }^{1}$; ALMEIDA FILHO, Silvio Humberto Cardoso de ${ }^{1}$; OLIVEIRA, \\ Laís Matos ${ }^{1}$; PIRES, Daniel Ananias de Assis ${ }^{1}$; AGUIAR, Ana Cássia Rodrigues de ${ }^{1}$; \\ SOUZA, Criszoel Ferreira ${ }^{1}$; ANTUNES, Cláudia Ribeiro ${ }^{1}$
}

\author{
${ }^{1}$ Universidade Estadual de Montes Claros, Centro de Ciências Exatas e Tecnológicas, Departamento de \\ Ciências Agrárias, Janaúba, Minas Gerais, Brasil. \\ E-mail para correspondência: vicente.rocha@unimontes.br
}

\section{RESUMO}

Objetivou-se avaliar a cinética de fermentação ruminal dos fenos de diferentes frações da parte aérea de variedades de mandioca, pela técnica semiautomática de produção de gases. $\mathrm{O}$ experimento foi conduzido em um delineamento em blocos casualizados, arranjado em um esquema fatorial $4 \times 3$, sendo quatro variedades de mandioca (Amarelinha, Sabará, Olho roxo e Periquita) e três frações da parte aérea (terço superior, sobra de plantio e planta inteira). As leituras de pressão dos gases foram realizadas por intermédio de transdutor de pressão e, posteriormente ajustadas para o volume de gases. Foram avaliadas a produção cumulativa de gases, as frações solúvel e insolúvel potencialmente degradável da MS, a taxa de degradação da MS, as degradabilidades potencial e efetiva da MS, a fração indegradável da MS, o potencial máximo de produção de gases, a taxa de produção de gases e o tempo de colonização. A produção de gases aumentou tendendo a se estabilizar por volta de 48 horas e observou-se um maior desaparecimento da matéria seca entre o tempo zero e 24 horas de fermentação. Os valores de produção cumulativa de gases (PCG) dos fenos analisados tiveram uma produção máxima de $50 \mathrm{ml}$ ao final das 96 horas de fermentação. $\mathrm{O}$ feno do terço superior da variedade Amarelinha, por apresentar melhores degradabilidade potencial $(64,17 \%)$ e efetiva $(55,65 \%)$ da matéria seca e maior potencial máximo de produção de gases $(35,69 \mathrm{~mL} / \mathrm{g}$ de $\mathrm{MS})$, em relação às demais variedades, demonstra superioridade nutricional.

Palavras-chave: degradabilidade, digestibilidade, forragem, ruminantes

\section{SUMMARY}

Aimed to evaluate thekinetics of ruminal fermentation of hays of different fractions of the aerial parts of cassava varieties by technical semiautomatic gas production. The experiment was conducted in a randomized block design, arranged in a $4 \times 3$ factorial design, four varieties of cassava (Amarelinha, Sabará, OlhoRoxo e Periquita) and three fraction of shoots (upper, left over planting and whole plant) Pressure readings were made of gases through pressure transducer and subsequently adjusted to the volume of gases. Were evaluated the cumulative gas production, potentially degradable insoluble fraction and soluble fraction of MS, the degradation rate of DM, the potential and effective degradability of DM, the undegradable fraction of $\mathrm{DM}$, the maximum potential gas production, the rate gas production and colonization time. There was an increase in gas production with a tendency of stabilization around a 48 hours period and a greater decrease in dry matter between zero and 24 hours fermentation period. The values of cumulative gas production (PCG) hay analyzed had a maximum output of $50 \mathrm{~mL}$ at the end of 96 hours of fermentation.The hay of Amarelinha's superior third was considered the most nutritional kind due to its betters degradability potential $(64.17 \%)$, effective dry matter $(55.65 \%)$, and greater maximal potential of gas production $(35.69 \mathrm{~mL} / \mathrm{g} \mathrm{DM})$ when compared to the other varieties studied.

Keywords: degradability, digestibility, roughage, ruminant 


\section{INTRODUÇÃOO}

A utilização de resíduos agroindustriais e outros ingredientes de potencial regional, utilizados de forma planejada, normalmente no período crítico do ano, pode melhorar a eficiência dos sistemas de produção pecuária. (ARAÚJO et al., 2009; CARVALHO JUNIOR et al., 2009; CRUZ et al., 2006; OLIVEIRA et al., 2009; PIRES et al., 2009) A parte aérea da mandioca (ramas mais folhas) é um alimento volumoso que apresenta bom valor nutritivo para os ruminantes (MIRANDA et al., 2008; FERREIRA et al., 2007; SOUZA et al., 2011), principalmente em função dos teores médios de proteína bruta $(17,60 \%)$ e NDT $(54,52 \%)$ (SOUZA, et al., 2012), podendo ser introduzida na dieta na forma de feno.

Visando uma forragem de melhor valor nutritivo, tem-se recomendado utilizar apenas o terço superior da parte aérea para a alimentação dos ruminantes, enquanto que, para a produção de manivas de qualidade requer somente o terço médio e inferior das ramas, eliminando a parte herbácea superior da planta. Além disso, a composição nutricional e a produtividade do feno da parte aérea da cultura de mandioca dependem de algumas variáveis como variedade, idade da planta, espaçamento, adubação e condições edafoclimáticas. (MODESTO et al., 2004; MOTA et al., 2011; NUNES IRMÃO et al., 2008)

Trabalhos realizados (CARVALHO et al, 2006; FIGUEIREDO et al, 2006; NUNES IRMÃO et al., 2008) sobre o uso de diferentes frações da parte aérea de variedades de mandioca na forma de feno foram baseados em análises bromatológicas, avaliações agronômicas e estudos com degradabilidade in situ. Segundo Giraldo et al. (2006), os sistemas in vitro, que incluem a técnica de produção de gases, são cada vez mais empregados na análise dos nutrientes utilizados pelos ruminantes, em virtude do baixo custo, rápida execução, confiabilidade, possibilidade de avaliação de grande quantidade de alimentos por ensaio e por utilizar poucos animais fistulados. Dessa forma objetivou-se, por meio deste trabalho, avaliar a cinética de fermentação ruminal por meio da técnica in vitro semiautomática de produção de gases, dos fenos de diferentes frações da parte aérea de quatro variedades de mandioca.

\section{MATERIAL E MÉTODOS}

O experimento foi conduzido na Fazenda Experimental da Universidade Estadual de Montes Claros UNIMONTES, localizada no município de Janaúba, Norte de Minas Gerais e no Laboratório de Análises de Alimentos do Departamento de Ciências Agrárias da UNIMONTES, campus de Janaúba. Utilizou-se o delineamento em blocos casualizados, com esquema fatorial $4 \times 3$, quatro variedades de mandioca (Manihot esculenta Crantz "Amarelinha", Manihot esculenta Crantz "Olho Roxo", Manihot esculenta Crantz "Periquita" e Manihot esculenta Crantz "Sabará") e três frações da parte aérea (planta inteira, terço superior e sobras de plantio) com quatro repetições cada. A escolha das variedades utilizadas foi baseada na frequência com que as mesmas eram utilizadas pelos produtores da região, ou seja, foram escolhidas as mais frequentemente cultivadas. Os fenos, que constituíram os tratamentos desta pesquisa, foram produzidos a partir desse experimento.

$\mathrm{O}$ plantio foi efetuado usando quatro canteiros (parcelas) com quatro linhas por variedade, seguindo as 
recomendações técnicas para a cultura e as metodologias tradicionais de cultivo empregadas pelos produtores locais, procedendo-se a coleta do material aos oito meses de idade, no respectivo estádio fenológico indicado para a colheita da raiz.

As plantas de cada canteiro foram separadas em três partes iguais, e isoladamente utilizadas para a produção de forragem com as seguintes frações da parte aérea: a) forragem composta pela parte aérea total, b) forragem composta apenas pelo terço superior da parte aérea e c) forragem composta pela parte aérea restante após a produção de manivas necessárias para novo plantio na mesma área. Essas forragens foram individualmente picadas em tamanho médio de partícula de $2 \mathrm{~cm}$ e manualmente homogeneizadas (Tabela $1)$.

Tabela 1. Composição química dos fenos de diferentes frações da parte aérea (FA) (TS - terço superior, SP - sobra de plantio e PI - planta inteira) de quatro variedades de mandioca

\begin{tabular}{lccccccc}
\hline Variedades & Frações & MS & PB & Cinzas & FDN & FDA & Lignina \\
\hline Amarelinha & TS & 92,0 & 20,06 & 8,53 & 72,85 & 44,91 & 14,23 \\
& SP & 91,4 & 17,29 & 8,11 & 77,62 & 52,13 & 17,61 \\
Sabará & PI & 91,2 & 13,99 & 6,67 & 79,78 & 55,89 & 18,54 \\
& TS & 91,8 & 20,70 & 8,64 & 71,76 & 45,81 & 16,94 \\
& SP & 92,0 & 18,76 & 8,42 & 77,47 & 56,47 & 19,17 \\
Olho Roxo & PI & 90,8 & 15,15 & 7,09 & 82,63 & 55,68 & 19,99 \\
& TS & 91,8 & 20,35 & 8,65 & 71,55 & 43,59 & 18,56 \\
& SP & 93,1 & 16,04 & 7,60 & 77,38 & 48,28 & 19,60 \\
Periquita & PI & 92,3 & 13,64 & 6,38 & 79,95 & 52,19 & 19,40 \\
& TS & 93,2 & 21,51 & 8,47 & 73,57 & 41,33 & 18,14 \\
Média & SP & 91,8 & 18,54 & 7,84 & 78,96 & 54,70 & 19,14 \\
& PI & 90,8 & 15,20 & 6,48 & 82,11 & 55,01 & 19,33 \\
& & 91,8 & 17,60 & 7,74 & 77,14 & 50,50 & 18,38 \\
\hline
\end{tabular}

MS = matéria seca; $\mathrm{PB}=$ proteína bruta; FDN = fibra em detergente neutro; FDA = fibra em detergente ácido.

No processo de cura (secagem) para a produção do feno, a forragem fresca foi distribuída em cima de lona plástica em camada de 2 - $3 \mathrm{~cm}$ de espessura. Esse material foi mantido ao sol, sendo periodicamente revirado (visando à homogeneização na desidratação), até atingir o ponto de feno de material picado (entre $10 \%$ e $15 \%$ de umidade). Depois de prontos os fenos, o material foi pesado, homogeneizado e pré-seco em estufa de ventilação forçada a cerca de $55^{\circ} \mathrm{C}$ até peso constante, em seguida foi moído em moinho de facas com peneira de malha de $1 \mathrm{~mm}$ para análises posteriores.

Foram determinados os teores de matéria seca (MS), proteína bruta (PB), cinzas, fibra em detergente neutro (FDN), fibra em detergente ácido (FDA) e lignina. Com exceção das análises de FDN e FDA, feitas segundo Van Soest et al. (1991), as demais análises seguiram as recomendações descritas por Silva \& Queiroz (2006). 
A estrutura do delineamento em blocos ao acaso mantida a campo, para controlar o efeito de fertilidade do solo, foi preservada para o ensaio de produção cumulativa de gases, com a finalidade de se obter as repetições do experimento.

A técnica in vitro semiautomática de produção de gases foi conduzida de acordo com Maurício et al. (1999). A incubação foi feita em frascos de vidro com capacidade para $160 \mathrm{~mL}$ que previamente ao experimento foram lavados com água destilada e secos em estufa. Posteriormente, foram injetados aos frascos dióxido de carbono $\left(\mathrm{CO}_{2}\right)$ e adicionados aproximadamente 1 grama das amostras a serem analisadas, pesando-se em balança digital, conforme os tratamentos propostos. Foram utilizados dois frascos por tratamento (réplicas) e frascos controle contendo apenas o meio de cultura e o inóculo. Para cada frasco, foram adicionados manualmente $90 \mathrm{~mL}$ de meio de cultura conforme Theodorou et al. (1994). Os frascos foram vedados com rolhas de borracha $(14 \mathrm{~mm})$ e para evitar que qualquer tipo de fermentação ocorresse, os frascos foram mantidos a $4{ }^{\circ} \mathrm{C}$ durante a noite em geladeira comum. No dia seguinte, cinco horas antes da inoculação, os frascos foram removidos da geladeira para estufa a $39^{\circ} \mathrm{C}$ até o momento da inoculação. Para coleta do líquido ruminal (inóculo), foram utilizados dois bovinos machos providos de cânula ruminal permanente. A coleta foi realizada manualmente no saco ventral do rúmen com auxílio de um pano e, posteriormente, houve a homogeneização dos inóculos provenientes dos dois animais, sendo, então, acondicionados em garrafa térmica previamente aquecida $\left(39^{\circ} \mathrm{C}\right) \mathrm{e}$ imediatamente levada ao laboratório. No laboratório, procedeu-se à filtragem do conteúdo em camada dupla de gaze com injeção contínua de $\mathrm{CO}_{2}$ e mantido em banho-maria, seguido imediatamente da inoculação.

A inoculação foi realizada através da injeção de $10 \mathrm{~mL}$ do inóculo por frasco através de seringa plástica graduada. Imediatamente após a inoculação, os frascos tiveram a pressão estabilizada através da inserção de agulhas $(25 \mathrm{~mm}$ x $7 \mathrm{~mm}$ ) nas tampas dos frascos. As agulhas foram posteriormente retiradas, os frascos manualmente agitados e colocados em estufa a $39^{\circ} \mathrm{C}$ e deu-se o início da contagem dos tempos de fermentação.

As leituras de pressão foram tomadas em maior frequência durante o período inicial de fermentação e reduzidas posteriormente $(0,4 ; 6 ; 8 ; 10 ; 12 ; 15$; $19 ; 24 ; 30 ; 36 ; 48 ; 72$ e $96 \mathrm{~h})$, sendo que após as leituras de 0,12, 24, 48 e 96 horas dois frascos eram removidos de cada tratamento para a determinação da degradabilidade.

A pressão dos gases foi obtida utilizando-se o equipamento Datalogger Universal Logger AG100, um equipamento de bancada dotado de entrada analógica em que foi conectado o manípulo com uma agulha $(0,7 \mathrm{~mm})$ fixada em sua ponta para perfurar as rolhas de borrachas sintéticas encaixadas nos frascos. Este equipamento possui um botão de disparo na parte superior do manípulo para ser acionado para que o registro da pressão (psi) seja efetuado.

$\mathrm{O}$ volume foi medido por meio de uma seringa graduada $(20 \mathrm{~mL})$ nos tempos predeterminados $(0 ; 6 ; 12 ; 24 ; 48$ e 96 horas) também com uma agulha acoplada $(0,6 \mathrm{~mm})$. Imediatamente após a inoculação foi realizada a leitura inicial com o objetivo de padronizar a pressão e descartar o volume dos gases em todos os tubos. A partir da inserção da agulha inserida na rolha de borracha sintética, a pressão produzida no interior dos frascos foi verificada no leitor 
digital. Feita a leitura da pressão, a obtenção do volume de gases foi realizada puxando-se o êmbolo da seringa até que a pressão do transdutor de pressão retornasse ao valor zero.

Para quantificação da produção de gases provenientes do tampão e do líquido do rúmen, foram incubados dois frascos contendo apenas estes componentes. Para cada tempo de leitura, o volume de gás dos frascos com amostra foi subtraído do volume obtido nos frascos sem amostras. Ao serem obtidos os valores de pressão e de volume em cada tempo, estes foram somados aos valores das leituras anteriores, possibilitando assim a construção da curva correspondente à fração solúvel para cada tempo de incubação.

O desaparecimento da matéria seca foi obtido pela relação entre a porcentagem do material inicialmente incubado e o resíduo após os períodos de $0,12,24$, 48 e 96 horas de fermentação. O resíduo da degradação foi obtido por meio da filtragem do conteúdo de cada frasco em cadinhos de porosidade 1 e posterior secagem em estufa a $100^{\circ} \mathrm{C}$ por 12 horas.

Os dados de produção cumulativa de gases oriundos da fermentação de cada tratamento foram utilizados no modelo de France et al. (1993):

$\mathrm{Y}=\mathrm{A}\{1-\exp [(-\mathrm{b}(\mathrm{t}-\mathrm{L})-\mathrm{c}) \mathrm{x}(\sqrt{ } \mathrm{t}-\sqrt{ } \mathrm{L})]\}$

Em que,

$Y=$ produção cumulativa de gases $(\mathrm{mL})$;

$A=$ potencial máximo de produção de gases;

$L=$ tempo de colonização (lag time);

$b$ e $c=$ taxas fracionais constantes;

Uma taxa fracional combinada à produção de gases $(\mu)$ foi calculada como:

Em que,

$$
\mu=b+c / 2 \sqrt{ } t
$$

$\mu=$ taxa de produção de gases;

$b$ e $c=$ taxas fracionais constantes;

$\mathrm{t}=$ tempo de incubação em horas.
Para ajustar os dados de degradabilidade às $0,6,12,24,48$ e 96 hs, foram utilizados os modelos matemáticos propostos por Mehrez \& Ørskov (1977) e Ørskov \& McDonald (1979), que possibilitaram estimar as degradabilidades potencial (DP) e efetiva (DE):

$$
\begin{gathered}
D P=A-t \leq L \\
\mathrm{DP}=\mathrm{a}+\mathrm{b}\left(1-\mathrm{e}^{-\mathrm{c} \times \mathrm{t}}\right)->t>L,
\end{gathered}
$$

Em que:

$\mathrm{DP}=$ degradabilidade do alimento $(\%)$ no tempo t (horas);

$\mathrm{A}=$ fração prontamente solúvel (\%);

a e $\mathrm{b}=$ parâmetros do modelo, cuja soma $(\mathrm{a}+\mathrm{b})$ corresponde numericamente à degradabilidade potencial do alimento; e $\mathrm{c}=$ taxa de degradação (\%/hora).

Calculou-se também a fração solúvel potencialmente fermentescível do alimento (B):

$$
B=(a+b)-A \text { ou } 100-(A+C),
$$

Em que:

$\mathrm{C}=$ fração indegradável (calculada como 100-DP).

A degradabilidade efetiva (DE) dos alimentos foi calculada da seguinte forma:

Em que:

$$
\mathrm{DE}=(\mathrm{a}+\mathrm{b}) /[\mathrm{c} /(\mathrm{c}+k p)]
$$

$\mathrm{kp}=$ taxa de passagem do alimento (\%/hora) pelo rúmen e foi considerada como 5\%/hora, que representa o consumo para um animal de média produção.

As estimativas dos parâmetros descritos no modelo matemático foram realizadas utilizando-se métodos interativos não lineares. Estes resultados ajustados, por estimativas de quadrados mínimos, foram obtidos a partir do uso do método Gauss - Newton, por meio do procedimento NLIN, com o auxílio do programa SAS. (SAS INSTITUTE, 1999). 
Para obtenção dos modelos estatísticos que medem a relação entre o volume de gases produzido durante a fermentação e a pressão (psi) utilizou-se o estudo de correlação por meio da linha de comando MANOVA do procedimento GLM de SAS. Uma vez detectada a correlação satisfatória (acima de $85 \%$ ) e significativa entre o volume e a pressão, utilizou-se a opção SELECTION=STEPWISE na linha de comando MODEL do procedimento GLM do SAS, para que a seleção do melhor modelo fosse feita automaticamente entre os modelos testados (linear, quadrático e cúbico). (SAS INSTITUTE, 1999)

Depois de obtidos os valores do volume acumulado de gases, taxa de degradação "c" e o tempo de colonização, os mesmos foram submetidos à análise de variância por meio do programa SISVAR (FERREIRA, 2011), além destes, os parâmetros de degradabilidade A, B, c, FI, DP e DE. E quando a análise de variância apresentou significância as médias de tratamentos (variedades e formas de aproveitamento) foram comparadas pelo teste de Scott-Knott ao nível de 5\% de probabilidade pelo SISVAR (Ferreira, 2011), sendo avaliados os efeitos de variedade, fração da parte aérea e interação destes fatores.

\section{RESULTADOS E DISCUSSÃO}

Os dados de pressão variaram de 0 a 5,0 psi e os de volume entre 0 e $22,0 \mathrm{~mL}$ para os fenos. Os tempos de leitura permitiram a obtenção de valores de pressão abaixo de 7,0 psi, de acordo com as recomendações de Theodorou et al. (1994) (Figura 1). Segundo esses autores, valores de pressão acima de 7,0 psi causam instabilidade na correlação entre as variáveis e alterações no crescimento microbiano.

A equação predita para os dados deste trabalho foi: $\mathrm{V}_{(\mathrm{ml})}=3,367 \mathrm{X}+4,037$, $\left(\mathrm{R}^{2}=0,86\right)$ em que $\mathrm{V}=$ volume $(\mathrm{mL})$ e $\mathrm{P}$ $=$ pressão $(\mathrm{psi})$, onde apresentou um comportamento linear, diferente aos obtidos por Azevedo et al. (2008) que foi: $\mathrm{V}=0,1178 \mathrm{P} 2+4,7295 \mathrm{P},\left(\mathrm{R}^{2}=0,99\right) \mathrm{e}$ da equação obtida por Maurício et al. (1999), onde, $\mathrm{V}(\mathrm{ml})=-0,004+4,43 \mathrm{P}$ $+0,051$ P2, $(\mathrm{R} 2=0,99)$ ou em estudo realizado na Universidade de ReadingInglaterra, onde também desenvolveram uma equação quadrática entre pressão e volume, a qual foi utilizada para estimar o volume obtido pela seringa na técnica manual de produção de gases. (THEODOROU et al., 1994) Assim, fica evidenciada a importância da adaptação do sistema através de equações para avaliação dos alimentos em diferentes altitudes. De acordo com Maurício et al. (1999), esta modificação levou a uma redução no erro do operador, maior velocidade de leitura e aumento da capacidade do sistema.

Nota-se que a produção de gases aumentou no decorrer do período de fermentação, tendendo a se estabilizar por volta de 48 horas, e observa-se uma maior taxa de desaparecimento da matéria seca (DMS) entre o tempo zero e 24 horas de fermentação (Figura 2). A diferença na degradação final (96 horas) que variou entre 41,70 e 59,0\% da MS nos fenos pode ter sido influenciada pela quantidade de parede celular apresentada nas diferentes forragens. 
Rev. Bras. Saúde Prod. Anim., Salvador, v.15, n.3, p.528-543 jul./set., 2014 http://www.rbspa.ufba.br ISSN 15199940

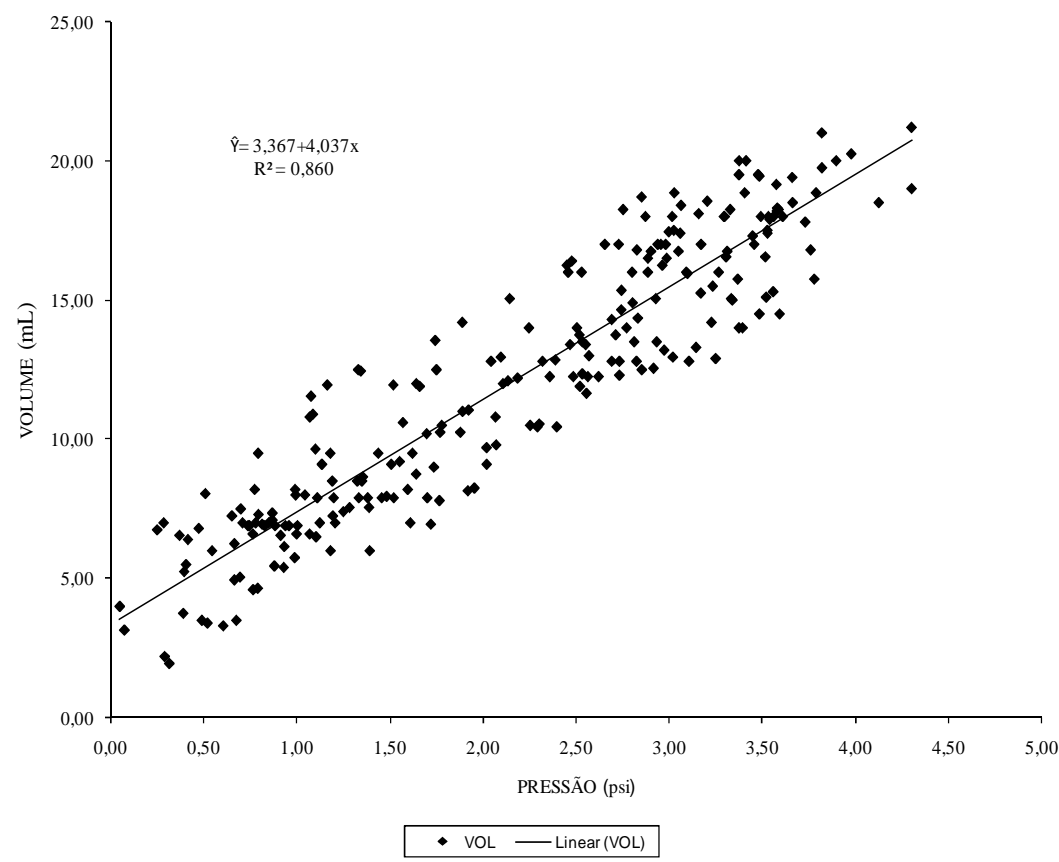

Figura 1. Pressão e volume obtido durante o ensaio de produção de gases usando como substratos os fenos das diferentes frações da parte aérea das quatro variedades de mandioca ( $\mathrm{psi}=$ libra por polegada ao quadrado)

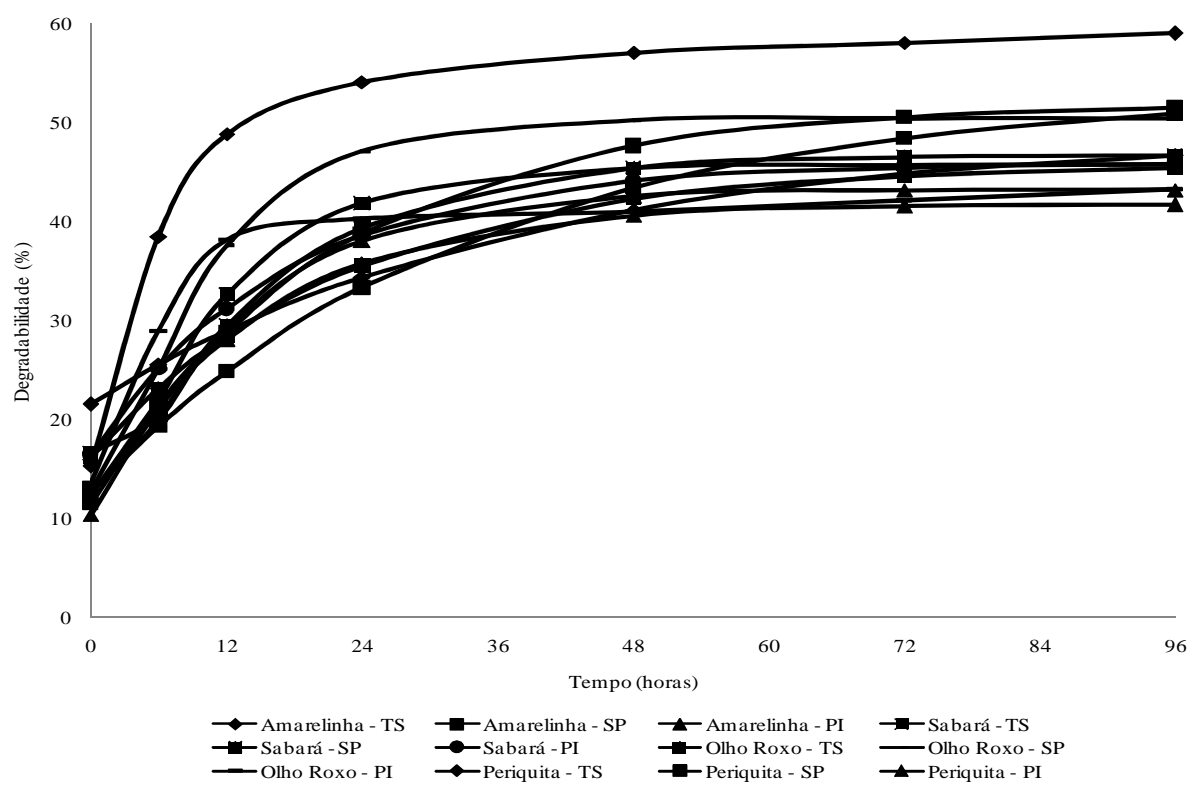

Figura 2. Desaparecimento da matéria seca dos fenos das diferentes frações da parte aérea das quatro variedades de mandioca nos tempos de 6, 12, 24, 48 e 96 horas de fermentação 
A produção de gases é reflexo da fermentação total do substrato e, consequentemente, do desaparecimento da MS. Segundo Bueno et al. (2005), os sistemas de produção de gases in vitro proporcionam uma estimativa da digestibilidade da matéria seca (MS) e são um indicador direto dos produtos finais produzidos, como a produção de gases, e indireta como ácidos graxos de cadeia curta (AGCC), os quais são a principal fonte de energia dos ruminantes. Os gases surgem diretamente da degradação microbiana dos alimentos e indiretamente da reação do tampão com os ácidos gerados como resultado da fermentação. (Velásquez et al., 2010)

Nos tempos iniciais de fermentação, a figura 2 ilustra uma taxa de degradação mais elevada para o feno da variedade Periquita na fração terço superior, e a partir de 6 horas de fermentação, a variedade Amarelinha, sob a mesma fração, se destacou das demais variedades, mantendo-se superior até 96 horas. Na figura 2, observa-se que o feno da variedade Periquita na fração planta inteira demonstra os menores valores de degradabilidade, sendo que esta apresenta uma das maiores concentrações de FDN $(82,11 \%)$, de FDA $(55,01 \%)$ e de lignina $(19,33 \%)$ (Tabela 1). Kunkel et al. (2006), trabalhando com a correlação da FDN e FDA de leguminosas tropicais com parâmetros de cinética de fermentação ruminal, mostraram que o aumento no teor de FDN e a elevação do teor de FDA das leguminosas tiveram correlação negativa com a taxa de degradação.

No período entre zero e doze horas de fermentação foram obtidas as maiores produções de gases (Figura 3), fato provavelmente ligado à fermentação dos carboidratos prontamente disponíveis, mostrando que frações facilmente fermentáveis são degradadas nas primeiras horas.

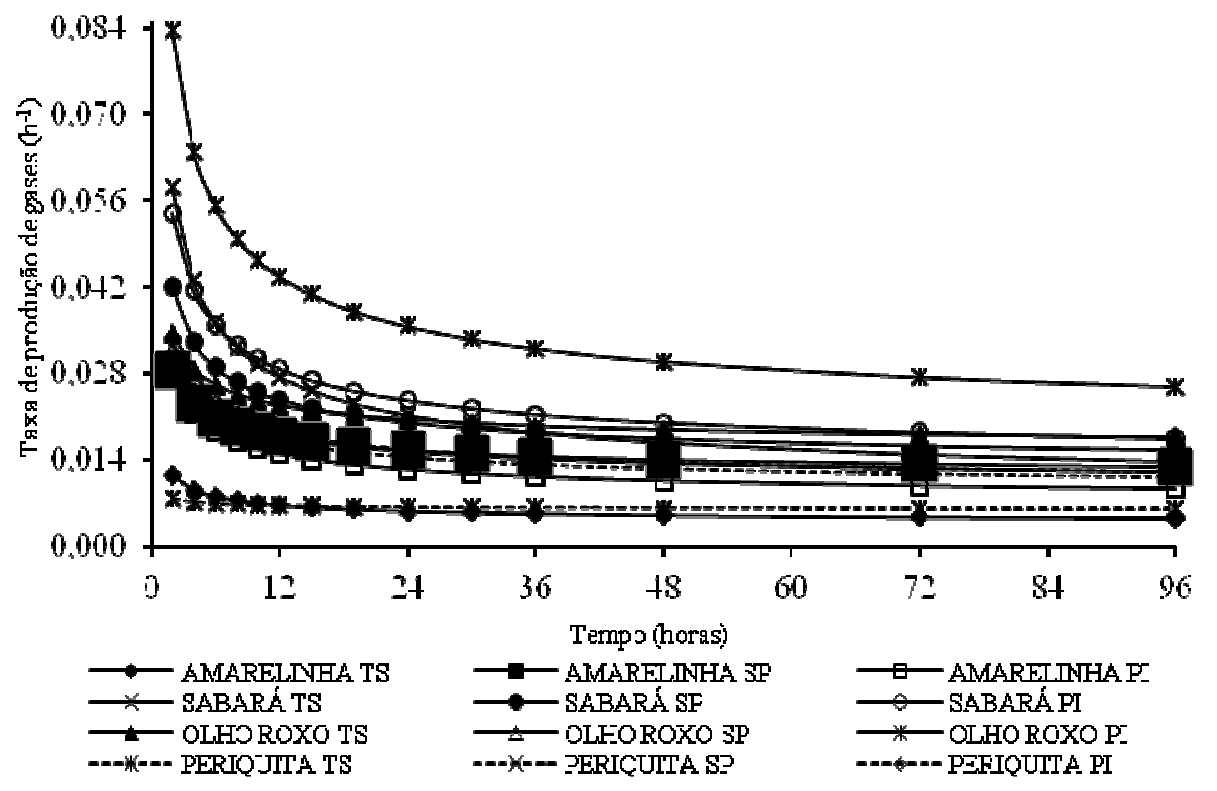

Figura 3.Taxa de produção de gases por tempo de fermentação (h) dos fenos de diferentes frações da parte aérea de quatro variedades de mandioca 
Desta forma, pode-se sugerir que a variedade Olho Roxo na planta inteira é a que, provavelmente, possui maior concentração de substratos solúveis, pois apresentou a curva do gráfico mais elevada, conforme figura 3. Seguida pelo feno da planta inteira da variedade Sabará. Em contrapartida, o feno da variedade Amarelinha na fração terço superior é o que demonstra menor taxa de produção de gases, mantendo-se praticamente constante durante todo o período de incubação. Na composição química, o feno das sobras de plantio da variedade Amarelinha apresenta teor de FDN de $77,62 \%$ e $52,33 \%$ de FDA
(Tabela 1), valores maiores quando comparados ao feno da variedade Olho Roxo no seu terço superior, componentes estes que podem interferir na taxa de fermentação.

Os valores de produção cumulativa de gases (PCG) dos fenos analisados tiveram uma produção máxima de $50 \mathrm{ml}$ ao final das 96 horas de fermentação. Observou-se uma maior produção de gases para o feno da variedade Olho Roxo na fração planta inteira, possivelmente devido a maior concentração de material facilmente fermentável (Figura 4).

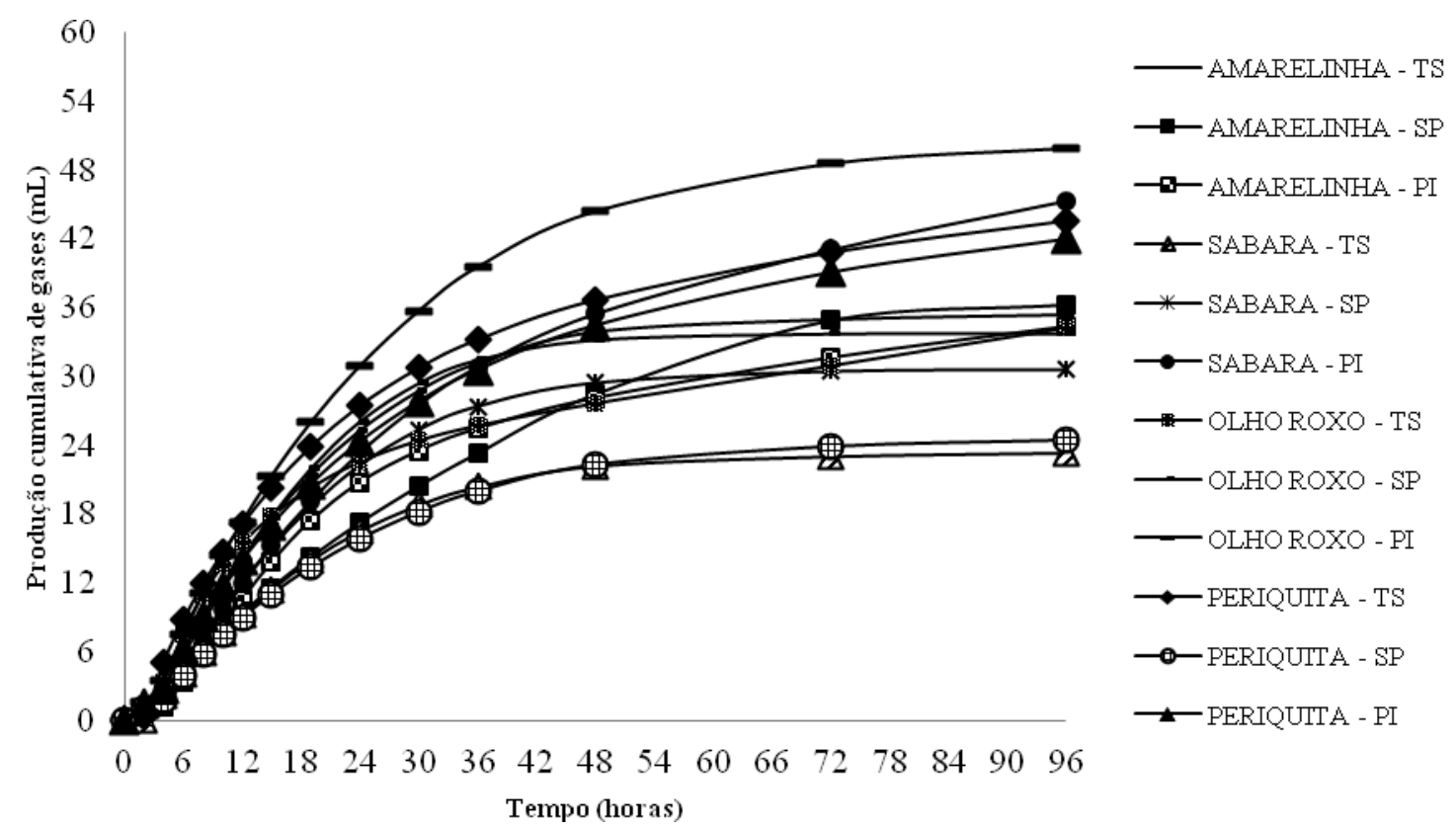

Figura 4. Produções cumulativas de gases (PCG) (em $\mathrm{ml} / \mathrm{g}$ de $\mathrm{MS}$ ) $\mathrm{x}$ tempo de fermentação dos fenos de diferentes frações da parte aérea de quatro variedades de mandioca

Observa-se menor produção cumulativa de gases para os fenos das variedades Sabará na fração terço superior e da variedade Periquita na fração sobras de plantio durante todo o tempo de fermentação. Sabe-se que dietas que proporcionam altos teores de proteína bruta apresentam baixa produção de gases (KHAZAAL et al., 1995) e para estes fenos, do terço superior da variedade Sabará e das sobras do plantio da variedade Periquita, a proteína bruta 
apresenta valores superiores, 20,7\% e $18,54 \%$, respectivamente, causando, portanto, uma redução no crescimento microbiano e consequentemente na produção de gases, quando comparado ao valor de proteína da variedade de maior produção, com $13,64 \%$.

Conforme o resultado da análise de variância, verificou-se que tanto as variedades quanto as frações da parte aérea dos fenos de mandioca avaliados apresentaram efeito significativo $(\mathrm{P}<0,05)$ sobre os parâmetros ruminais para a fração prontamente solúvel (A), fração insolúvel potencial fermentável (B) e taxa de degradação (c) da matéria seca como mostra a Tabela 2, havendo efeito de interação desses fatores sob as variáveis avaliadas.

Tabela 2. Fração prontamente solúvel (A), fração insolúvel potencial fermentável (B) e taxa de degradação por hora (c) da matéria seca dos fenos de diferentes frações da parte aérea (terço superior - TS, sobras do plantio - SP e planta inteira - PI) de quatro variedades de mandioca

\begin{tabular}{|c|c|c|c|c|c|c|c|c|c|}
\hline \multirow{3}{*}{ Variedades } & \multicolumn{3}{|c|}{ A } & \multicolumn{3}{|c|}{ B } & \multicolumn{3}{|c|}{$\mathrm{C}$} \\
\hline & \multicolumn{9}{|c|}{ Frações da parte aérea } \\
\hline & $\mathrm{TS}$ & SP & PI & TS & SP & PI & $\mathrm{TS}$ & SP & PI \\
\hline Amarelinha & $11,41^{\mathrm{Ba}}$ & $12,74^{\mathrm{Ba}}$ & $4,68^{\mathrm{Aa}}$ & $52,76^{\mathrm{Bb}}$ & $40,59^{\mathrm{Aa}}$ & $38,54^{\mathrm{Aa}}$ & $0,12^{\mathrm{Bb}}$ & $0,04^{\mathrm{Aa}}$ & $0,08^{\mathrm{Ab}}$ \\
\hline Sabará & $2,41^{\mathrm{Aa}}$ & $6,55^{\mathrm{Aa}}$ & $16,50^{\mathrm{B}} \mathrm{b}$ & $43,34^{\mathrm{Bb}}$ & $40,21^{\mathrm{Ab}}$ & $29,42^{\mathrm{Aa}}$ & $0,10^{\mathrm{Ba}}$ & $0,07^{\mathrm{Aa}}$ & $0,06^{\mathrm{Aa}}$ \\
\hline Olho Roxo & $16,20^{\mathrm{Bb}}$ & $0,79^{\mathrm{Aa}}$ & $3,65^{\mathrm{Aa}}$ & $29,66^{\text {Aa }}$ & $49,66^{\mathrm{Ab}}$ & $36,61^{\mathrm{Aa}}$ & $0,04^{\mathrm{Aa}}$ & $0,11^{\mathrm{Bb}}$ & $0,10^{\mathrm{Ab}}$ \\
\hline Periquita & $21,54^{\mathrm{Bb}}$ & $11,55^{\mathrm{Ba}}$ & $10,36^{\mathrm{Ba}}$ & $27,35^{\text {Aa }}$ & $40,41^{\mathrm{Ab}}$ & $31,41^{\mathrm{Aa}}$ & $0,03^{\mathrm{Aa}}$ & $0,05^{\mathrm{Aa}}$ & $0,07^{\mathrm{Aa}}$ \\
\hline $\mathrm{CV}(\%)$ & & 55,03 & & & 16,85 & & & 47,1 & \\
\hline
\end{tabular}

Letras maiúsculas idênticas significam semelhança estatística em uma mesma coluna; letras minúsculas idênticas representam semelhança estatística em uma mesma linha. Pelo teste de Scott \& Knott ao nível de $5 \%$ de significância. ${ }^{1} \mathrm{CV}=$ coeficiente de variação.

$\mathrm{Na}$ fração prontamente solúvel (A) observa-se que a variedade Sabará, no feno do terço superior foi inferior às demais variedades. A variedade Amarelinha destacou-se, no feno das sobras de plantio com $12,74 \%$ de fração A. Todavia, no feno da planta inteira, a variedade Sabará apresentou maior percentual de fração solúvel da MS. Já a variedade Periquita destacou-se nas três frações da parte aérea, com valores de $21,54,11,55$ e $10,36 \%$, para os fenos do terço superior, sobras do plantio e planta inteira, respectivamente. Para variedade Amarelinha não houve diferença entre os fenos das diferentes frações da parte aérea. Nas variedades Olho Roxo e Periquita, o feno do terço superior mostrou maior percentual de fração solúvel, comparado aos fenos das demais frações. A maior produção cumulativa de gases apresentada pelo feno da planta inteira da variedade Olho Roxo, não é compatível com a fração solúvel da MS deste feno, que foi menor em relação ao feno do terço superior, entretanto, pode ser justificado pelo percentual, relativamente alto, da fração $\mathrm{B}$, que representa a fração insolúvel e potencialmente degradável da MS.

Para fração potencialmente degradável (fração B) da matéria seca (MS), conforme Tabela 2, observa-se que as variedades Amarelinha e Sabará, no feno do terço superior, destacaram-se. No entanto, nos fenos das frações sobras de plantio e planta inteira não houve diferenças entre variedades. 
Portanto, uma maior participação do terço superior da parte aérea da mandioca para produção de forragem pode implicar em um maior potencial de degradação da forragem produzida.

Quanto às taxas de degradação, as variedades Amarelinha e Sabará, no feno do terço superior, apresentaram maiores taxas. A menor taxa de degradação da fração terço superior da variedade Periquita pode ser atribuída às características físicas, tamanho $\mathrm{e}$ densidade de partículas, e estruturais, como o grau de lignificação da parede celular que são capazes de dificultar o acesso microbiano a essa fração. (Van Soest, 1994) Já os fenos das sobras de plantio e planta inteira da variedade Olho Roxo foram superiores ao feno do terço superior, com $0,11 \%$ e $0,10 \%$, respectivamente. Além disso, o feno da fração planta inteira também se destacou para a variedade Amarelinha com $0,08 \%$ de fração c. Portanto, as diferentes taxas de degradação encontradas nos alimentos analisados podem ter sido influenciadas pelos teores de MS, parede celular e conteúdo de carboidratos solúveis.

A degradabilidade efetiva e a potencial da MS tiveram comportamentos semelhantes, apresentando maiores valores para o feno do terço superior da variedade Amarelinha (Tabela 3). Carvalho et al. (2006) verificaram degradabilidade potencial da matéria seca de $57,10 \%$ para parte aérea da mandioca. Já Figueiredo et al. (2006), trabalhando com feno da parte aérea da mandioca, encontraram valores médios de $63,9 \%$ e $73,9 \%$ para degradabilidade efetiva e potencial, respectivamente. Esses resultados demonstram que os efeitos de variedade e fração da parte aérea são fatores que influenciam a qualidade da forragem produzida $\mathrm{e}$ consequentemente $\mathrm{o}$ potencial de utilização na alimentação animal.

Tabela 3. Degradabilidade efetiva (DE), degradabilidade potencial (DP) e fração indegradável (FI) da matéria seca dos fenos de diferentes frações da parte aérea (terço superior - TS, sobras do plantio - SP e planta inteira - PI) de quatro variedades de mandioca

\begin{tabular}{|c|c|c|c|c|c|c|c|c|c|}
\hline \multirow{3}{*}{ Variedades } & \multicolumn{3}{|c|}{$\overline{\mathrm{DE}}$} & \multicolumn{3}{|c|}{ DP } & \multicolumn{3}{|c|}{ FI } \\
\hline & \multicolumn{9}{|c|}{ Frações da parte aérea } \\
\hline & $\mathrm{TS}$ & SP & PI & $\mathrm{TS}$ & SP & PI & $\mathrm{TS}$ & SP & PI \\
\hline Amarelinha & $55,65^{\mathrm{Bb}}$ & $23,56^{\mathrm{Aa}}$ & $27,44^{\mathrm{Aa}}$ & $64,17^{\mathrm{Bb}}$ & $53,33^{\text {Aa }}$ & $43,22^{\mathrm{Aa}}$ & $35,83^{\mathrm{Aa}}$ & $46,68^{\mathrm{Ab}}$ & $56,78^{\mathrm{Ab}}$ \\
\hline Sabará & $30,73^{\mathrm{Aa}}$ & $30,05^{\mathrm{Aa}}$ & $32,09^{\mathrm{Aa}}$ & $45,76^{\mathrm{Aa}}$ & $46,76^{\mathrm{Aa}}$ & $45,92^{\mathrm{Aa}}$ & $54,25^{\mathrm{Ba}}$ & $53,25^{\mathrm{Aa}}$ & $54,08^{\mathrm{Aa}}$ \\
\hline Olho roxo & $28,59^{\mathrm{Aa}}$ & $34,83^{\mathrm{Aa}}$ & $31,85^{\mathrm{Aa}}$ & $45,85^{\mathrm{Aa}}$ & $50,45^{\mathrm{Aa}}$ & $40,25^{\mathrm{Aa}}$ & $54,15^{\mathrm{Ba}}$ & $49,55^{\mathrm{Aa}}$ & $59,7^{5 \mathrm{Aa}}$ \\
\hline Periquita & $30,19^{\mathrm{Aa}}$ & $28,34^{\mathrm{Aa}}$ & $26,84^{\mathrm{Aa}}$ & $48,89^{\mathrm{Aa}}$ & $51,33^{\mathrm{Aa}}$ & $41,75^{\mathrm{Aa}}$ & $51,12^{\mathrm{Ba}}$ & $48,04^{\mathrm{Aa}}$ & $58,26^{\mathrm{Aa}}$ \\
\hline $\mathrm{CV}(\%)$ & & 23,14 & & & 16,8 & & & 15,16 & \\
\hline
\end{tabular}

Letras maiúsculas idênticas significam semelhança estatística em uma mesma coluna; letras minúsculas idênticas representam semelhança estatística em uma mesma linha. Pelo teste de Scott \& Knott ao nível de 5\% de significância. ${ }^{1} \mathrm{CV}$ - Coeficiente de variação.

Quanto à fração indegradável (FI), o feno do terço superior da variedade Amarelinha apresentou o menor valor entre as variedades e as partes testadas, isto devido ao menor teor de lignina, que é indigestível.

Neste experimento, observou-se que para o potencial máximo de produção de gases (A) (Tabela 4), as variedades 
Amarelinha e Periquita, no feno do terço superior, foram superiores às demais variedades. Já nas frações sobras do plantio e planta inteira não houve diferenças entre variedades, resultados estes que corroboram aqueles verificados para fração insolúvel e potencialmente degradável da MS. Segundo Tomich et al. (2003), o potencial máximo de produção de gases pode ser influenciado pela relação propionato/acetato, resultante da fermentação de um alimento, podendo interferir no volume de gases, e resultar em maior ou menor produção de gases. Isto pode ajudar a explicar as diferenças observadas entre variedades apenas na fração do terço superior, que apresenta, de modo geral, maior percentual de fração potencialmente degradável em relação às demais frações.

Tabela 4. Potencial máximo de produção de gases (A) em $\mathrm{mL} / \mathrm{g}$ de $\mathrm{MS}$, tempo de colonização (L) em horas e taxa de produção de gases $(\mu)$ em $\mathrm{mL} / \mathrm{g}$ de $\mathrm{MS} / \mathrm{h}$ em 96 horas de incubação dos fenos de diferentes frações da parte aérea (terço superior - TS, sobras do plantio - SP e planta inteira - PI) de quatro variedades de mandioca

\begin{tabular}{|c|c|c|c|c|c|c|c|c|c|}
\hline \multirow{3}{*}{ Variedades } & \multicolumn{3}{|c|}{ A } & \multicolumn{3}{|c|}{$\mathrm{L}$} & \multicolumn{3}{|c|}{$\mu$} \\
\hline & \multicolumn{9}{|c|}{ Frações da parte aérea } \\
\hline & TS & SP & PI & TS & SP & PI & TS & SP & PI \\
\hline Amarelinha & $35,69^{\mathrm{Ba}}$ & $31,85^{\mathrm{Aa}}$ & $32,99^{\mathrm{Aa}}$ & $2,32^{\mathrm{Ab}}$ & $0,87^{\mathrm{Aa}}$ & $2,32^{\mathrm{Ab}}$ & $0,04^{\mathrm{Aa}}$ & $0,02^{\mathrm{Aa}}$ & $0,03^{\mathrm{Aa}}$ \\
\hline Sabará & $23,82^{\mathrm{Aa}}$ & $30,66^{\mathrm{Ab}}$ & $34,55^{\mathrm{Ab}}$ & $1,69^{\mathrm{Aa}}$ & $2,60^{\mathrm{Ba}}$ & $2,78^{\mathrm{Aa}}$ & $0,02^{\mathrm{Aa}}$ & $0,03^{\mathrm{Aa}}$ & $0,03^{\mathrm{Aa}}$ \\
\hline Olho roxo & $27,29^{\mathrm{Aa}}$ & $33,78^{\mathrm{Ab}}$ & $39,65^{\mathrm{Ab}}$ & $1,65^{\mathrm{Aa}}$ & $2,18^{\mathrm{Ba}}$ & $2,38^{\mathrm{Aa}}$ & $0,12^{\mathrm{Bb}}$ & $0,04^{\mathrm{Aa}}$ & $0,04^{\mathrm{Aa}}$ \\
\hline Periquita & $32,77^{\mathrm{Ba}}$ & $28,13^{\mathrm{Aa}}$ & $37,20^{\mathrm{Aa}}$ & $1,54^{\mathrm{Aa}}$ & $2,66^{\mathrm{Ba}}$ & $2,56^{\mathrm{Aa}}$ & $0,03^{\mathrm{Aa}}$ & $0,05^{\mathrm{Aa}}$ & $0,04^{\mathrm{Aa}}$ \\
\hline $\mathrm{CV}(\%)$ & & 16,91 & & & 36,77 & & & 85,74 & \\
\hline
\end{tabular}

Letras maiúsculas idênticas significam semelhança estatística em uma mesma coluna; letras minúsculas idênticas representam semelhança estatística em uma mesma linha. Pelo teste de Scott \&Knott ao nível de $5 \%$ de significância. ${ }^{1} \mathrm{CV}$ - Coeficiente de variação.

O tempo de colonização (L) oscilou de 0,87 a 2,66 horas (Tabela 4). Este parâmetro representa o tempo entre o início da incubação e a ação microbiana sobre a amostra testada. Nogueira et al.(2006) relataram que o tempo de colonização está relacionado com o teor de carboidratos solúveis das forrageiras. Nos fenos das sobras de plantio, as variedades Sabará, Olho Roxo e Periquita apresentaram maiores tempos de colonização em relação à Amarelinha, enquanto que as frações terço superior e planta inteira não diferiram entre variedades. Um menor tempo de colonização poderia ser justificado pela maior concentração de substratos prontamente fermentáveis para a microbiota ruminal. (RIBAS et al., 2007)

As taxas de produção de gases $(\mu)$, um parâmetro que depende do tempo de incubação de cada alimento, variaram de 0,02 a $0,12 \mathrm{~mL} / \mathrm{h}$ para a MS dos fenos (Tabela 4). Para esta variável, o feno do terço superior da variedade Olho Roxo foi superior aos fenos das demais variedades $(p<0,05)$, entretanto, demonstrou menor potencial máximo de produção de gases em relação aos fenos das variedades Amarelinha e Periquita. De acordo com Tomich et al.(2003), partindo do princípio que o gás produzido na fermentação reflete a 
degradação da amostra testada, a taxa e o potencial máximo de produção de gases são, provavelmente, as principais características para avaliar a qualidade de forrageiras pelas técnicas de produção de gases. Entretanto, segundo Pereira et al. (2005), forrageiras de melhor qualidade apresentam valores mais altos de degradabilidade potencial e elevadas taxas de degradação.

Sendo assim, considerando apenas o potencial de produção de gases, os fenos do terço superior das variedades Amarelinha e Periquita apresentam maior potencial de utilização na alimentação animal. Todavia, por apresentar melhores coeficientes de degradabilidade potencial e efetiva da matéria seca e maior potencial máximo de produção de gases, o feno do terço superior da variedade Amarelinha, em relação às demais variedades, demonstra superioridade nutricional.

\section{AGRADECIMENTOS}

À Fapemig, pelo auxílio financeiro, e ao $\mathrm{CNPq}$ e Capes, pelo auxílio com bolsas.

\section{REFERÊNCIAS}

ARAÚJO, M.J.; MEDEIROS, A.N.; CARVALHO, F.F.R.; SILVA D.S.;

CHAGAS, E.C.O. Consumo e digestibilidade dos nutrientes em cabras Moxotó recebendo dietas com diferentes níveis de maniçoba. Revista

Brasileira de Zootecnia, v.38, n.6, p.1088-1095, 2009.

AZEVEDO, M.M.R.; VASCONCELOS,V.R.; PIMENTEL, J.C.M.; PINTO, B.I.S.; ARAÚJO NETO, J.C.; CARVALHO, A.A. Estimativa do Volume de Gases por Meio de Equação de Regressão para
Implantação da Técnica In Vitro Semiautomática de Produção de Gases.

Revista Ciência e Produção Animal, v.10, n.1, p.15-20, 2008.

BUENO, I.C.S.; CABRAL FILHO, S.L.S.; GOBBO, S.P.; LOUVANDINI H.; VITTI, D.M.S.S., ABDALLA, A.L.Influenceofinoculum source in a gasproductionmethod. Animal Feed Science and Technology, v.123-124, n.1, p.95-105, 2005.

CARVALHO, G.G.P.; PIRES, A.J.V.; VELOSO, C.M.; DETMANN, E.; SILVA, F.F.; SILVA, R.R. Degradabilidade ruminal do feno de alguns alimentos volumosos para ruminantes. Arquivo Brasileiro de Medicina Veterinária e Zootecnia, v.58, n.4, p.575-580, 2006.

CARVALHO JÚNIOR, J.N.; PIRES, A.J.V.; SILVA, F.F.; VELOSO, C.M.; CRUZ, C.L.S.; CARVALHO, G.G.P. Desempenho de ovinos mantidos com dietas com capim-elefante ensilado com diferentes aditivos. Revista Brasileira de Zootecnia, v.38, n.6, p.994-1000, 2009.

CRUZ, F.G.G.; FILHO, M.P.; CHAVES, F.A.L. Efeito da substituição do milho pela farinha da apara de mandioca em rações para poedeiras comerciais. Revista Brasileira de Zootecnia, v.35, n.6, p.2303-2308, 2006.

FERREIRA, D.F. SISVAR: A computerstatisticalanalysis system. Ciência e Agrotecnologia, v.35, n. 6, p.1039-1042, 2011.

FERREIRA, G.D.G.; OLIVEIRA, R.L.; CARDOSO, E.C.; MAGALHÃES, A.L.R.; BRITO, E.L. Valor nutritivo de co-produtos da mandioca. Revista Brasileira de Saúde e Produção Animal [online], v.8, n.4, p.364-374, 2007. 
Rev. Bras. Saúde Prod. Anim., Salvador, v.15, n.3, p.528-543 jul./set., 2014 http://www.rbspa.ufba.br ISSN 15199940

FIGUEIREDO, M.P.; SOUZA, L.F.; FERREIRA, J.Q. Cinética da degradação ruminal da matéria seca da haste, da raiz, do feno da parte aérea e da silagem de raiz de mandioca (ManihotesculentaCrantz) tratada com uréia. Brazilian Journal of Veterinary Research Animal Science, v.43, n.1, p.11-17, 2006.

FRANCE, J.; DHANOA, M.S.; THEODOROU, M.K.; LISTER, S.J.; DAVIES, D.R.; ISAC, D. A model to interpret gas accumulation profiles associated with in vitro degradation of ruminant feeds. Journal of Theorical Biology, v.163, n.1, p.99-111, 1993.

GIRALDO, L.A.; GUTIÉRREZ, L.A.; SÁNCHEZ, J.; BOLÍVAR, P.A.

Relación entre presión y volumen para elmontaje de La técnica in vitro de producción de gas em Colombia.

Livestock Research for Rural Development, v. 18, n.6, 2006.

Disponível em:

<http://www.cipav.org.co/1rrd/1 rrd18/6 /gira18075.htm/>. Acesso em: 26 ago. 2010.

KHAZAAL, K.; DENTINHO, M.T.; RIBERRIO, J.M.; OERSKOV, E.R. Prediction of apparent digestibility and voluntary feed intake of hays fed to sheep: comparison between using fiber component, in vitro digestibility or characteristics of gas productionor nylon bag degradation. Animal Science, v.61, p.527-538, 1995.

KUNKEL, L.J.; KOZLOSKI, G.V.; MEZZOMO, M.P.; MARTINS, A.A.; ORLANDI.T.; FLUCK, A.C. A correlação da FDN e FDA deleguminosas tropicais com parâmetros de cinética de fermentação ruminal. In: JORNADA ACADÊMICA INTEGRADA, 26., 2006, Santa Maria. Anais... Santa Maria, RS: Universidade
Federal de Santa Maria, 2006. Disponível em:<http://portal.ufsm.br/jai/anais/evento s.htm>. Acessoem: 26 abr. 2012.

MAURICIO, R.M.; MOULD, F.L.; DHANOA, M.S. A semi-automated in vitro gas production technique for ruminants feedstuff evaluation.Animal Feed Science Technology, v.79, p.321330, 1999.

MOTA, A.D.S.; ROCHA JÚNIOR, V.R.; SOUZA, A.S. de; REIS, S.T. dos; TOMICH, T.R.; CALDEIRA, L.A.; MENEZES, G.C. de C.; COSTA, M.D. Revista Brasileira de Zootecnia, v.40, n.7, p.1466-1473, 2011.

MEHREZ, A.Z.; ORSKOV, E.R. A study of the artificial fibre bag technique for determining the digestibility of feed in the rumen. JournalofAgricultural Science, v.88, n.3, p.645-650, 1977.

MIRANDA, L.F.; PEREIRA, E.S.; RODRIGUEZ, N.M.; GONTIJO NETO, N.M.; ARRUDA, A.M.V. Avaliação da composição protéica e aminoacídica de forrageiras tropicais. Revista Caatinga, v.21, n.1, p.36-42, 2008.

MODESTO, E.C.;SANTOS, G.T.; VILELA, D.; SILVA, D.C.; FAUSTINO, J.O.; DETMANN, E.; ZAMBOM, M.A.; MARQUES, J.A. Caracterização químicobromatológica da silagem do terço superior da rama de mandioca. Acta Scientiarum Animal Science, v.26, n.1, p.137-146, 2004.

NOGUEIRA, U.T.; MAURÍCIO, R.M.; GONÇALVES, L.C. Comparação de substratos com diferentes quantidades de carboidratos solúveis utilizando a técnica in vitro semi-automática de produção de gases. Arquivo Brasileiro de MedicinaVeterinária e Zootecnia, v.58, n.4, p.633-641, 2006. 
NUNES IRMÃO, J.; FIGUEIREDO, M.P.; OLIVEIRA, B.M.; RECH, J.L.; FERREIRA, J.Q.; PEREIRA, L.G.R. Composição química do feno da parte aérea da mandioca em diferentes idades de corte. Revista Brasileira de Saúde e Produção Animal [online], v.9, n.1, p.158-169, 2008 .

OLIVEIRA, J.B.; PIRES, A.J.V.; CARVALHO, G.G.P.; RIBEIRO, L.S.O.; CRUZ, J.F.; GARCIA, R.; CARVALHO JÚNIOR, J.N.; CHAGAS, D.M.T. Capim-elefante ensilado com casca de café, farelo de cacau ou farelo de mandioca. Revista Brasileira de Zootecnia, v.38, n.1, p.34-39, 2009.

ØRSKOV, E.R.; MCDONALD, I. The estimation of protein degradability in the rumen from incubation measurements weighted according to rate of passage. Journalof Agricultural Science, v.92, n.2, p.499-503, 1979.

PEREIRA, L.G.R.; MAURÍCIO, R.M.; GONÇALVES, L.C.; TOMICH, T.R.;RODRIGUES, J.A.S.; RODRIGUEZ, N.M. Avaliação das silagens de girassol (hibrido m734) obtidas em diferentes épocas de ensilagem pela técnicain vitrosemiautomática de produção de gases. Brazilian Journal of Veterinary Research Animal Science, v.42, n.4, p.276-283, 2005.

PIRES, A.J.V.; CARVALHO, G.G.P.; GARCIA, R.; CARVALHO JÚNIOR, J.N.; RIBEIRO, L.S.O.; CHAGAS, D.M.T. Fracionamento de carboidratos e proteínas de silagens de capimelefante com casca de café, farelo de cacau ou farelo de mandioca. Revista Brasileira de Zootecnia, v.38, n.3, p.422-427, 2009.
RIBAS, M.N.; GONÇALVES, L.C.; MAURÍCIO, R.M. Degradabilidade e cinética de fermentação ruminal das silagens de quatro híbridos de milho, avaliadas pela técnica in vitro semi automática de produção de gases. Revista Brasileira de Milho e Sorgo, v.6, n.2, p.223-233, 2007.

SAS INSTITUTE. User's Guide: statistics. Version 8.0.1. Cary, 1999.

SILVA, D.J.; QUEIROZ, A.C. Análise de alimentos: métodos químicos e biológicos. 3.ed. Viçosa: Universidade Federal de Viçosa, 2006. 235p.

SOUZA, A.S.de; ROCHA JÚNIOR, V.R.; MOTA, A.D.S.; PALMA, M.N.N.; FRANCO, M.O.; DUTRA, E.S.; SANTOS, C.C.R.dos; AGUIAR, A.C.R.; OLIVEIRA, C. R.; ROCHA, W.J.B. Valor nutricional de frações da parte aérea de quatro variedades de mandioca. Revista Brasileira de Saúde e Produção Animal [online], v.12, n. 2, p. 441-455, 2011.

SOUZA, A.S. de; ROCHA JÚNIOR, V.R.; MOTA, A.D.S.; ROCHA, W.J.B.; OLIVEIRA, C.R.; AGUIAR, A.C.R. de; SANTOS, C.C.R.dos; MENDES, G.A. Potencial forrageiro e valor nutricional do feno de diferentes frações da parteaérea de quatro variedades de mandioca. Revista Brasileira de Saúde e Produção Animal [online], v.13, n.3, p.604-618, 2012.

THEODOROU, M.K.; WILLIAMS, B.A.; DHANOA, M.S. A simple gas production method using apressure transducer to determine the fermentation kinetics of ruminant feeds. Animal Feed Science and Technology, v.48, n.3-4, p.185-197, 1994. 
Rev. Bras. Saúde Prod. Anim., Salvador, v.15, n.3, p.528-543 jul./set., 2014 http://www.rbspa.ufba.br ISSN 15199940

TOMICH, T.R.; GONÇALVES, L.C.; MAURÍCIO, R.M.; PEREIRA, L.G.R.; RODRIGUES, J.A.S. Composição bromatológica e cinética de fermentação ruminal de híbridos de sorgo com capim-sudão. Arquivo Brasileiro de Medicina Veterinária e Zootecnia, v.55, n.6, p.747-755, 2003.

VAN SOEST, P.J.; ROBERTSON, J.B.; LEWIS, B.A. Methods for dietary fiber, and nonstarch polysaccharides in relation to animal nutrition. Journal of Dairy Science, v.74, n.10, p.3583-3597, 1991.

VAN SOEST, P.J. Nutritional ecology of the ruminant. Ithaca: Cornell University Press, 1994. 476 p.
VELÁSQUEZ, P.A.T.;BERCHIELLI, T.T.; REIS, R.A.; RIVERA, A.R.; DIAN, P.H.M.; TEIXEIRA, I.A.M.A. Composição química, fracionamento de carboidratos e proteínas e digestibilidade in vitro de forrageiras tropicais em diferentes idades de corte. Revista Brasileira de Zootecnia, v.39, n.6, p.1206-1213, 2010.

Data de recebimento: 08/10/2013

Data de aprovação: 21/07/2014 